\title{
Urban Resilience in Post-Disaster Reconstruction: Towards a Resilient Development in Sichuan, China
}

\author{
Yan Guo* \\ School of Doctorate Studies, University IUAV of Venice (Istituto Università di Architettura di Venezia), 30125 Venice, Italy
}

\begin{abstract}
This article discusses the post-disaster urban resilience design framework in the case of post-disaster urban reconstruction in Sichuan after the Great Sichuan Earthquake (also known as the Wenchuan Earthquake) in May 2008 in China. The focus is on three main aspects of post-disaster urban reconstruction: sociospatial coherence, temporal continuity, and multistakeholder integration and communication. Critical interpretation of the government-guided reconstruction reveals that reconstruction was limited to the generic production and implementation of top-down planning. From the perspective of urban resilience, and through an alternative design scenario developed in this research, this article highlights an urban resilience design framework based on postdisaster development in the Sichuan city of Dujiangyan. By identifying the deficiencies of the governmental reconstruction where in many aspects resilience has not been considered, and by proposing the alternative where resilience has been considered to develop a better living, this research seeks to integrate urban resilience as a key aspect in the Sichuan reconstruction and as essential for developing the postdisaster city towards a more coherent, sustainable, and integral urban future.
\end{abstract}

Keywords Dujiangyan, Great Sichuan Earthquake, postdisaster reconstruction, design for urban resilience

\section{Introduction}

"Cities always sought resilience to the hazards they have faced. In this sense, resilience has been core to urbanism" (Coaffee, Wood, and Rogers 2009, 3). This article aims at examining the case of the Great Sichuan Earthquake reconstruction guided by the government from the perspective of urban resilience. It presents a contextual interpretation of the government-led reconstruction, in which urban resilience was not applied as an initial concept. The reconstruction has been used as an opportunity for territorial development, mostly focused on the extremely rapid economic recovery. In the city of Dujiangyan the generic top-down planning has caused sociospatial incoherence; the prompt massive urbanization has created discontinuity in the city's development taking

\footnotetext{
* E-mail: charles.yan.gore@gmail.com
}

little account of its urban history. Cooperation among multiple stakeholders could have been much more extensively promoted, but its absence from government-led reconstruction efforts have created urban fragmentation and are thus problematic. This raises questions on how urban resilience should be developed in the reconstruction, and "who should recover which aspect of the city, for whom, in what intention and by what mechanism" (Vale and Campanella 2005, 337).

Through a specific understanding of the concept of urban resilience in this relatively underdeveloped but rapidly urbanizing area in western China, the following discussion demonstrates that it is important to maintain the sociospatial coherence of "urbanity" in the existing urban area. It is also necessary to consider the history of the city over time. In addition, smooth communication among and integration of different stakeholders are fundamental to resilience building. By proposing a design framework based on the concept of urban resilience, this research presents an alternative integral design scenario for the post-disaster city of Dujiangyan, to integrate local resilience building into the government reconstruction process. With a perspective from urbanism, the scenario focuses on design proposals that contribute to the overall sociospatial coherence and temporal continuity in the post-disaster urban development of the case study area. The design scenario also explores the potential of multistakeholder integration, which contributes to a resilient reconstruction.

\section{Sichuan: Strategic Post-Disaster Reconstruction Guided By the Chinese Government}

On 12 May 2008, the catastrophic Great Sichuan Earthquake struck some of the most inhabited regions in western China, mostly in Sichuan Province. With a magnitude of 8.0 on the Richter scale, this earthquake caused 69,226 deaths, 17,923 people were listed as missing, 374,643 were injured, around 7.79 million houses collapsed and 24.59 million were damaged, resulting in direct economic losses of RMB 845.1 million yuan (approximately USD 134.2 million) ${ }^{\mathrm{ii}}$ (UNCRD $2009,3)$. Due to the grievous losses and the severe impacts of the disaster, the region attracted a tremendous amount of 
national and international attention, resulting in a three-day national mourning period and unprecedented post-earthquake relief and reconstruction efforts ${ }^{\mathrm{iii}}$ led by the Chinese government. Different from any other urban redevelopments in contemporary China, the post-disaster redevelopment of Sichuan has not only been a massive urban intervention to recover from the catastrophic impact of the earthquake on the Sichuan region and its local communities, but is also seen as a strategic opportunity for the territorial development of the area.

\subsection{The Government Plan for Reconstruction}

Within one month after the earthquake, a detailed ordinance of eighty bylaws in nine chapters, the Post-Wenchuan Earthquake Restoration and Reconstruction Ordinance, was approved for the Sichuan post-disaster reconstruction at the 11th executive meeting of the State Council of the People's Republic of China and was announced (State Council of the People's Republic of China 2008). With this Ordinance, the massive and rapid urban reconstruction process of Sichuan was officially initiated in a top-down fashion. The Ordinance stated the policies and schedules for the reconstruction in Sichuan. Policies for the reconstruction covers areas including spatial layout, urban housing, urban construction, rural construction, public services, infrastructure, industrial recovery, disaster prevention and reduction, ecological environments, mental care, policy measures, reconstruction funds, and plan implementation.

Each single bylaw in Chapter Four of the State Council Ordinance intends to guide a careful and strict planning scheme. Bylaw No. 31, for example, states that the establishment of post-earthquake recovery and reconstruction planning should integrate the relevant organizations and experts, and should sufficiently consult the post-disaster victims; significant decisions should be evaluated by corresponding experts in special discussions (State Council of the People's Republic of China 2008). Although the policy statements remained on an abstract level, they still clarified issues such as how the reconstruction planning should proceed, who should get involved at which stage of the process, and so on. In addition, this document proposed some innovative approaches to reconstruction planning, such as democratic decision making and a participatory process as suggested in Bylaw No. 31, as well as paying special attention to disaster risk areas, and suggestions to avoid future disaster risks as suggested in Bylaw No. 32. However, some of these suggestions remained as policy guidelines and was never reflected in detailed reconstruction planning and implementation.

This detailed official document was released by the central government within a short time after the disaster, which was incredibly efficient and fundamentally important for launching the reconstruction in a prompt manner. It also determined that the post-disaster reconstruction in Sichuan is an extremely organized and centralized planning action, principally led by the government.

\subsection{Potential Mediators between Top-Down and Bottom-Up Initiatives}

Although the post-disaster recovery of the Great Sichuan Earthquake is a government-led process, there have been various nongovernment organization (NGO) and nonprofit organization (NPO) involvements. In response to the practical demands, their assistance ranged from medical aid and finance management to technical expertise and knowledge provision, covering almost every area of disaster relief and recovery. The NGOs and NPOs have been constantly looking for possibilities and operating efficiently for constructive interventions. However, they have been excluded from the official reconstruction scheme, regardless of their areas of expertise. Our experience with some local NGOs during a planning workshop (Sichuan Workshop: Dujiangyan Dreams $)^{\text {iv }}$ suggested that this is a pervasive phenomenon in post-disaster Sichuan.

It is clear that NGO development in China was still at an early stage. But they could play an active role in integrating the top-down governance and bottom-up initiatives $(\mathrm{Ge}, \mathrm{Gu}$, and Deng 2010). Given the NGOs' power and efficiency in the relief phase and their huge and rapidly increasing number after the Great Sichuan Earthquake, ${ }^{v}$ it is not difficult to see that NGOs could have been a powerful and efficient mediator among multiple stakeholders, to improve the communication between the government and the public. However, this potentially very important resource was only tapped into during the relief phase and largely ignored in post-disaster reconstruction.

\subsection{Strategic Post-Disaster Territorial Development Programs}

Post-disaster reconstruction should not stop at rebuilding a city to the state before it was destroyed by the disaster, but use the opportunity to improve the city and its infrastructure and urban environment for a better living in the future. Especially in the Sichuan Earthquake case, with massive financial and material support from governmental authorities, various institutions, and individuals across the country and from around the world, the reconstruction became a rare opportunity of territorial development for many places in Sichuan. Several strategic territorial development programs have been promoted by the governments of various levels to achieve the development goals.

\subsubsection{Regional Development Plans}

Since the Small Town Construction Program initiated by the State Council of the People's Republic of China in the early 1980 s, by 2000 Sichuan had transformed 18,139 rural villages to small towns, pioneered a shift from rural to urban in the west of China, and developed a large number of small and medium enterprises in rural towns and villages. Sichuan was designated as a key region in China's West Development 
Program under the National 10th Five-Year Plan in 1999. In the National 11th Five-Year Plan from 2005, Sichuan established its role as a primary region in the program of Building a New Socialist Countryside, which has placed a central focus on rural communities and harmonious societal development. These programs (Kuang and Jiang 2010) set the social, economic, and spatial development context of pre-disaster Sichuan.

Sichuan has been a very strategic region in the territorial development of China, even before the earthquake in 2008 . Because of its strategic geographic location between the more urbanized regions in the east and the less urbanized regions in the west, Sichuan's development pushes the frontier of urban development from eastern China towards western China. Therefore, it has been significant to China's overall territorial tactics in the context of recent rapid urbanization. The opportunity of urbanizing through post-disaster reconstruction has great regional and local importance for areas severely affected by the earthquake. Other than achieving redevelopment in the damaged region, the reconstruction has also developed a visionary scenario for the region's long-term development. But the central planning approach continues to prevail-similar characteristics existed in urban development prior to the earthquake since the 1980 s and the post-disaster reconstruction, particularly that the reconstruction applied the same top-down approach to its planning and plan implementation.

\subsubsection{Post-Disaster Tourism}

The Sichuan Earthquake, in spite of its immense damages and losses, has been recognized as a rare opportunity of development by the Chinese government. It represents a form of Chinese optimism in which Crisis equals Hazards plus Opportunity. The strategy of developing post-disaster tourism is an example of this view. It aims to integrate the rich ecological and cultural resources to boost regional tourism development for a prompt economic recovery.

In line with the principle of turning the post-disaster area into a land of opportunity, the national government announced a territorial strategy of post-disaster tourism, soon after the post-disaster relief had started. The first intention of this policy has been to quickly recover the economy and basic infrastructure in designated areas. The key of this strategy has been to attract mainly domestic tourists who are emotionally motivated to contribute to the post-earthquake recovery to visit the disaster area, and to understand the local situation through personal experiences. It also intends to bring large numbers of potential tourists to the region to help the local economy through tourism consumption. The strategy has both educational and economic values.

In order to implement this strategy, the national and municipal governments have engaged many commercial developers for investment. The constructions started with recovering and upgrading the transport system and other urban infrastructure, then followed with tourism facilities, and finally opened up for commercial developments of related urban activities.

During the post-disaster recovery phase, which started approximately 3-18 months after the disaster, post-disaster tourism worked efficiently and successfully for the economic recovery. Through the implementation of this strategy, a major portion of the reconstructions on basic urban infrastructure and tourism facilities have been completed in a short time. The tourist center of Dujiangyan City, for example, was recovered in one year and was ready for post-disaster tourism activities in 2009. This approach aided the recovery process for post-disaster tourist cities.

\subsubsection{One-on-One Assistance Reconstruction Programs}

Another important strategy in Sichuan Earthquake postdisaster reconstruction is the one-on-one assistance program, which has played a critical role in the post-earthquake recovery. Different from previous post-disaster reconstructions, the central government of China appointed many municipalities of well-developed provinces and Direct-Controlled Municipalities (DCMs) ${ }^{\mathrm{vi}}$ from other parts of the country to assist the local municipalities in the disaster areas. Each of those external municipalities formed a one-on-one assistance partnership with one of the local disaster-affected cities and counties (Table 1) for the reconstruction. This has been the

Table 1. One-on-one assistance partnerships for the Sichuan Earthquake post-disaster reconstruction

\begin{tabular}{ll}
\hline \multicolumn{1}{c}{$\begin{array}{c}\text { Disaster-Affected Cities } \\
\text { and Counties }\end{array}$} & \multicolumn{1}{c}{$\begin{array}{c}\text { Supporting External } \\
\text { Municipalities from }\end{array}$} \\
\hline Sichuan Province & \\
\hline An County & Liaoning \\
Beichuan County & Shandong \\
Chongzhou City & Chongqing \\
Dujiangyan City & Shanghai \\
Hanyuan County & Hubei \\
Heishui County & Jilin \\
Jiange County & Heilongjiang \\
Jiangyou City & Henan \\
Li County & Hunan \\
Mao County & Shanxi \\
Mianzhu City & Jiangsu \\
Pengzhou City & Fujian \\
Pingwu County & Hebei \\
Qingchuan County & Zhejiang \\
Shifang City & Beijing ${ }^{\dagger}$ \\
Songpan County & Anhui \\
Wenchuan County & Guangdong \\
Xiaojin County & Jiangxi \\
\hline Gansu Province & \\
\hline Seriously affected areas in Gansu & Shenzhen \\
\hline Shaanxi Province & \\
\hline Seriously affected areas in Shaanxi & Tianjin ${ }^{\dagger}$ \\
\hline †: DCM. & \\
Source: UNCRD 2009. & \\
& \\
\hline
\end{tabular}


first, and so far the only, urban development strategy that cooperates on a territorial level on post-disaster urban reconstruction in China.

Under the one-on-one assistance program, competitions among the reconstruction teams composed of local and external partners were encouraged. The progress of all reconstruction teams has been presented on many public occasions. These teams were under great pressure to carry out a "best" paradigmatic reconstruction for the political achievement and social image of both the assisted and the assisting parties. For instance, the reconstruction team of disaster-affected Dujiangyan City and its one-on-one assisting partner Shanghai Municipality competed with that of Wenchuan County and municipalities from Guangdong Province. Competitions were through comparison of the reconstruction plans' productivity, implementation efficiency, construction quality, and so on. Such competition forces the participating teams to come up with broad innovative ideas and to use the resources more efficiently. As a result, it has accelerated the reconstruction progress and led to an incredibly rapid recovery.

\subsubsection{The Shanghai-Dujiangyan Urban Reconstruction Project}

To evaluate the efficacy of such a top-down approach of territorial development in an area prone to frequent earthquakes, a review of this process from a risk management point of view is necessary. Also important is the efficiency of economic recovery and the consideration or lack of consideration for sustainable local livelihoods and cultural sustainability. The one-on-one assistance partnership has also introduced some external architectural characteristics to the local built environment through the reconstruction. Some of these issues can be examined through the Dujiangyan and Shanghai assistance partnership case.
Dujiangyan, a county-level city of Chengdu Municipality, is a very significant small Chinese city of approximately 680,000 inhabitants (including 420,000 urban inhabitants), with a historic center based on the Dujiangyan Irrigation System that dates back to around 2250 years ago. The irrigation system, as the first man-made hydraulic irrigation system in human history, has been diverting water from the Min River to irrigate the West Sichuan Plain for thousands of years. The region has been one of the most irrigated and fertile territories in China throughout history. Therefore, the city of Dujiangyan is fundamentally important to the ecological landscape of the region and is tied to the region's agricultural profile because of its social and demographic characteristics, economic dynamics, and ecological settings. For its natural beauty and significance of hydraulic achievement, the Dujiangyan Irrigation System was designated a UNESCO World Heritage Site in 2000. It is a nationally renowned tourist site and has contributed increasingly to the tourism economy of the city as tourist activities have become more and more popular in China in recent decades. During the Sichuan Earthquake, many places in the historic center and within the first ring road of the city were seriously damaged; some districts within the second ring road suffered medium damages.

Appointed by the central government, Shanghai Municipality was responsible for assisting with the reconstruction of Dujiangyan during the first three years of the reconstruction period. The government authority that is responsible for executing the reconstruction launched an international competition on 12 July 2008, inviting ideas for Dujiangyan's reconstruction. Some of the proposals came up with an overscaled waterfront development scenario (see example in Figure 1) to promote a new Dujiangyan as a regional center for international tourism and leisure. This kind of postdisaster reconstruction plan does not adequately take into

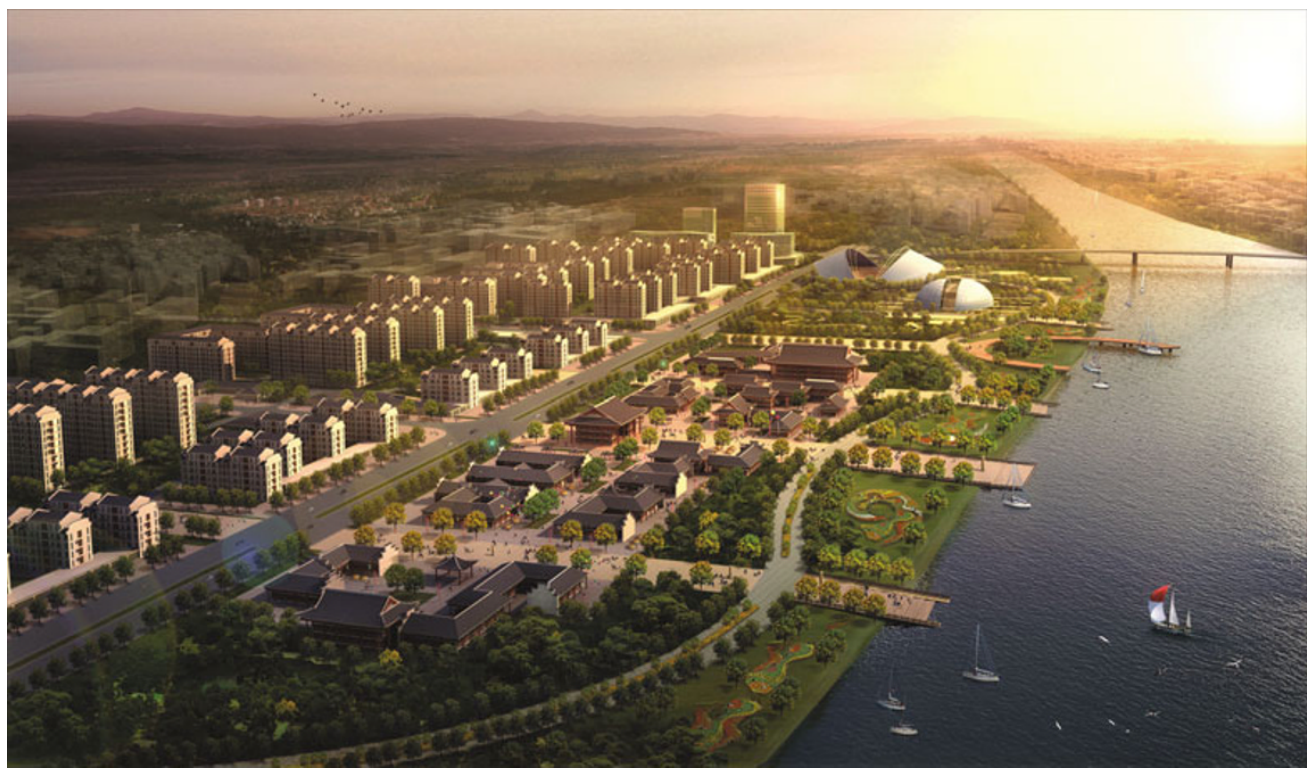

Figure 1. Post-disaster reconstruction scenario for touristic waterfront of Dujiangyan, Sichuan Province Source: Chengdu Planning and Management Bureau 2008. 
account Dujiangyan's special and significant agricultural and ecological profile. Megastructures of relief housing agglomerations (Figure 2) for tens of thousands of households now appear in some places in the relatively small city of Dujiangyan. Many housing projects were constructed neither at a moderate scale nor in the style of traditional Sichuan houses, but in the cosmopolitan and modern taste that is commonly seen and may well be appreciated in Shanghai (Figure 3).

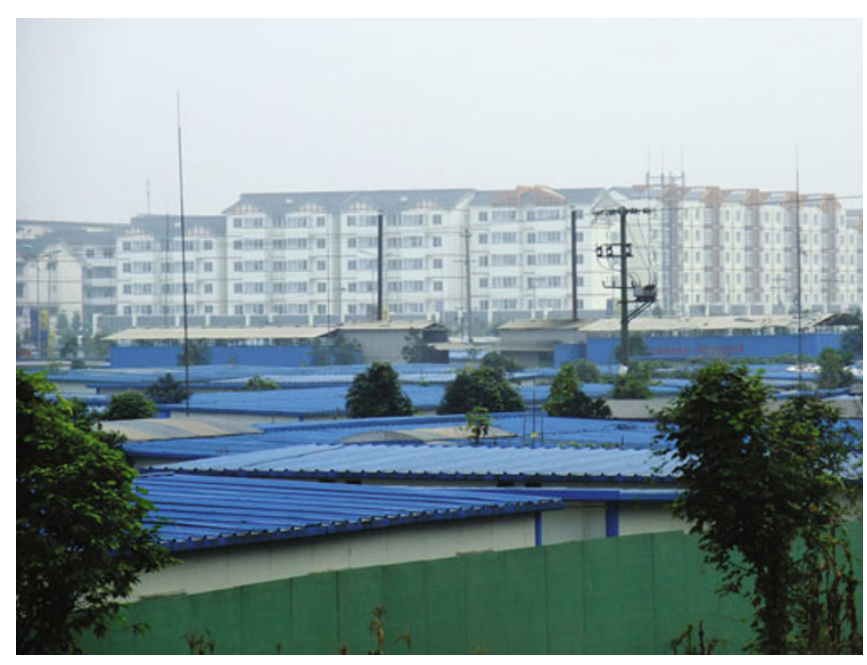

Figure 2. Relief housing agglomerations beside transitional disaster shelters in Dujiangyan, Sichuan Province in 2009 Photograph by the author, 3 July 2009.

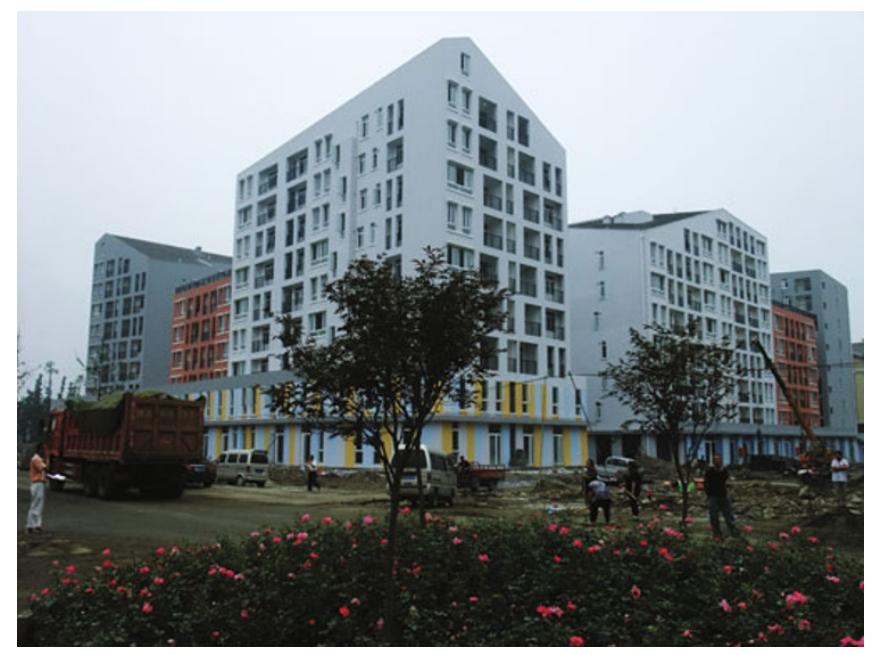

Figure 3. Post-disaster reconstruction housing project in Dujiangyan, Sichuan Province in 2010

Photograph by the author, 23 July 2010.

This kind of approach to reconstruction often leads to urban development at a scale and with a design that is out of context and lacks essential respect for the specific characteristics of a region. Such generic urban planning and design is context ignorance and low sustainability based solely on a common understanding of urbanism. It would also increase the risk of disasters and vulnerability for those who inhabit in this urban space, as well as create massive chaos in the resettlement of disaster victims. Fundamental sociospatial coherence is missing. In addition, the dominant top-down planning has always executed the reconstruction with a rapid schedule decided by higher-level government authority, in order to fulfill the emergent demand of recovery. This is associated to the competition for a "better" reconstruction that requires quick measurable results with an extreme emphasis on economic efficiency and construction productivity. With such a strong focus on efficiency and productivity in redevelopment urban reconstruction is often accelerated in ways that make it difficult to implement a holistic development approach that takes into account urban history and cultural traditions. Therefore, post-disaster planning has been inevitably limited to providing quantity of urban interventions, but has not provided quality of urban life. Furthermore, the lack of cooperation among stakeholders increases misunderstandings and conflicts. It does not help resilience building but makes communication between various stakeholders of post-disaster recovery problematic.

\section{A Critical Concept: Urban Resilience}

Resilience is a critical concept to guide urban reconstruction of a post-disaster territory and to reflect on the post-disaster urban condition of vulnerability. Examining the post-disaster urban reconstruction organized by the Chinese government in Sichuan from the perspective of resilience construction raises critical questions about the complex and paradoxical relationship between rapid urban reconstruction and urban resilience.

\subsection{From Disaster to Resilience}

Like disaster, resilience as a set of multidimensional concepts, tools, and characteristics, is site- and context-specific to various types of disasters in different places. To define resilience for urban projects, desirable characteristics for cities, and useful tools in a post-disaster practice, it is crucial to identify which type of resilience is key to the process of post-disaster redevelopment. It is important to specify urban resilience in a post-disaster territory.

Resilience was first defined by Holling as the time required for an ecosystem to return to an equilibrium or steady-state following a perturbation (Holling 1973; Gunderson 2000). This definition did not only view resilience in a systematic perspective, but it introduced resilience also with a temporal attribute. The push for resilience has been a response to existential or material vulnerability, insecurity, and change. Resilience can also be defined as a sociotechnical or even technocentric concept in many of its versions, from 
Timmerman's "capacity to adapt to stress from hazards and the ability to recover quickly from their impacts" (Timmerman 1981, 5) to Pelling's "capacity to adjust to threats and mitigate or avoid harm" (Pelling 2003, 5). Dovers and Handmer (1992), by reasoning on the resilience of social systems, distinguish the processes of adaptation of a society between proactive and reactive. A further distinction in conceptualizing socioecological system resilience is made between "specified" and "general" resilience. Specified resilience is the resilience "of what, to what" (Carpenter et al. 2001, 765). General resilience is "the resilience of all aspects of a system to unspecified, including novel and unforeseen, disturbances" (Resilience Alliance 2009).

\subsection{From General to Specific: Urban Resilience}

While natural disasters and environmental hazards are far from being exclusively urban experiences, the recent surge in events affecting large-scale conurbations has led to a significant shift towards analyzing the adaptive capacity of governance institutions and communities and how this might be utilized in developing a new "urban resilience" (BullKamanga et al. 2003; Pelling and High 2005). Social or community resilience is seen as the participation of citizens in the process of making the state of the society or community more resilient and in helping to manage threats and conditions of uncertainty, because shared and coordinated action can reduce collective vulnerability. At the urban level, the idea of critical infrastructure protection (CIP) or the protection of lifelines has become common. Godschalk argues that "resilient cities are constructed to be strong and flexible, rather than brittle and fragile. Their lifeline systems of roads, utilities and other support facilities are designed to continue functioning in the face of rising water, high winds, shaking ground, and terrorist attacks" (Godschalk 2003, 137). Goldstein (2011) argues that the communication between different stakeholders is also fundamental to the social aspect of urban resilience towards disasters, conflicts, or urban security risks.

The contribution of these emergent interdisciplinary studies on resilience emphasizes emergency planning and disaster management as an integrative and holistic exercise, which is seen as a collective responsibility, and refines the concept of urban resilience as both reactive and proactive to disasters.

\subsection{Urban Resilience in Sichuan Reconstruction}

In developing their historic perspective on urban resilience, Coaffee, Wood, and Rogers argue that "resilience is most effective when it involves a mutual and accountable network of civic institutions, agencies and individual citizens working in partnership towards common goals within a common strategy" (Coaffee, Wood, and Rogers 2009, 3). Vale and Campanella point out that "[...] the resilient city is a constructed phenomenon, not just in the literal sense that cities get reconstructed brick by brick, but in a broader cultural sense. Urban resilience is an interpretive framework proposed by local and national leaders and shaped and accepted by citizens in the wake of disaster. However equitable or unjust, efficient or untenable, that framework serves as the foundation upon which the society builds anew" (Vale and Campanella 2005, 353).

The debate on resilience and resilient city is helpful for finding clues on how cities could and should be recovered from disasters. Using the above frameworks to verify if the government-guided reconstruction in Sichuan has made the region more resilient, the following observations can be made:

Despite systematic organization and efficient implementation, several aspects of urban reconstruction can be better integrated in the process:

(1) From the perspective of urbanism, there should be more considerations of social and spatial coherence for the recovery or redevelopment of the urbanity of the post-quake cities, that is, comprehensive recovery of urban fabric (built structures), urban system (system that operates and organizes the urban dynamics), and urban livelihoods. While mentioned in the government's visions of the recovery plans these concepts have hardly been implemented in the governmentguided reconstruction.

(2) A resilient reconstruction should also consider the specific urban profile and configuration of the place, to redevelop a site- and context-specific urbanity, instead of reconstructing everything with the generic vision of a top-down plan.

(3) Different processes of reconstruction and recovery should be more integrated with progressive collaboration; resilient reconstruction cannot be achieved by focusing on individual aims (in the case of Sichuan, the economic recovery) and implementing plans in a great rush or even at the same time as they are made.

(4) Improved integration and collaboration in terms of public-private partnerships would be very beneficial. The expansion of NGO involvement in the process of mediating, reflecting, and engaging top-down approaches and bottom-up initiatives would be beneficial. As concluded in a report on identifying resilience after the Sichuan Earthquake: "engineering management needs to include social metrics further if it is to achieve the outcomes that China now seeks" (Potangaroa, Wang, and Chang 2008, 6).

\section{Seeking Urban Resilience: An Alternative Scenario for Development in Dujiangyan}

From the perspective of an architect, in the following section this author focuses on how an alternative design scenario for the reconstruction can contribute to the urban resilience of the post-disaster city of Dujiangyan in Sichuan Province. The scenario development is guided by a post-disaster resilience design framework, which in the aspects of urbanism focuses on sociospatial coherence in the urban design and temporal continuity in the urban development strategy. 


\subsection{The Urban System before and after the Earthquake Impact}

To find clues to urban resilience in the original setting of Dujiangyan, analyses in the alternative proposal started with exploring the urban system of the city, before and after the earthquake. Due to its unique UNESCO World Heritage Site status, its particular cultural landscape of hydraulics, and its demographic and ecological settings of agriculture, although relatively small in population and area, Dujiangyan as a city plays a significant role in the region. There are five types of urban subsystems to be noted: production, retail, dining, leisure, and tourism. They represent the major urban activities of Dujiangyan. By mapping the facilities and related transportation networks in these five types of urban activities in the city (Figure 4), this work identifies the allocation of different functions in the original urban fabric. By overlaying the layers of the five urban subsystems, Figure 5a illustrates the original pattern of the urban system before the earthquake. From these maps, we can see that the city has a systematic and well-developed transportation network connecting to its surrounding rural areas, which represents a strong connection for agricultural trading activities. Yet, seeing from this figure, the two concentrations of the city's daily activities are around the historic center, where the irrigation system and the tourism center are close to, and around the intercity bus station that locates at the cross of the main axis formed by the highway (connecting the provincial capital Chengdu and the inner mountain region to Tibet) and the first ring road, where the city's main bus station is located. Both of these elements of the city, namely the places of daily activities and the route network that provides access to these places, are fundamentally important to the urbanity of Dujiangyan.

Instead of just considering the damage of the urban fabric itself, this study pays particular attention to the damages of the urban system. Figure $5 \mathrm{~b}$ indicates the extent of damages of the urban system after the earthquake. This set of mapping analyses together reveals a fact that although the serious damage did not necessarily affect all of the built urban fabric of the city and the rural areas, the majority of the most active

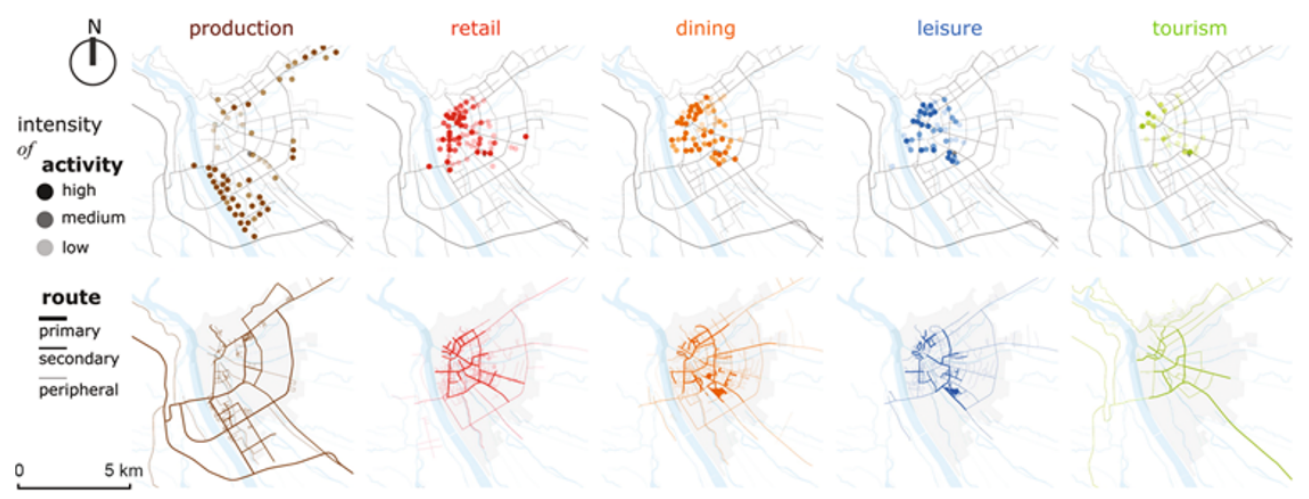

Figure 4. The original urban systems of Dujiangyan, Sichuan Province

Brown: production; red: retail; orange: dining; blue: leisure; green: tourism. The transparency of the dots indicates the intensity of the activities, and the width of the lines indicates the intensity of flow.

Source: Guo 2010.

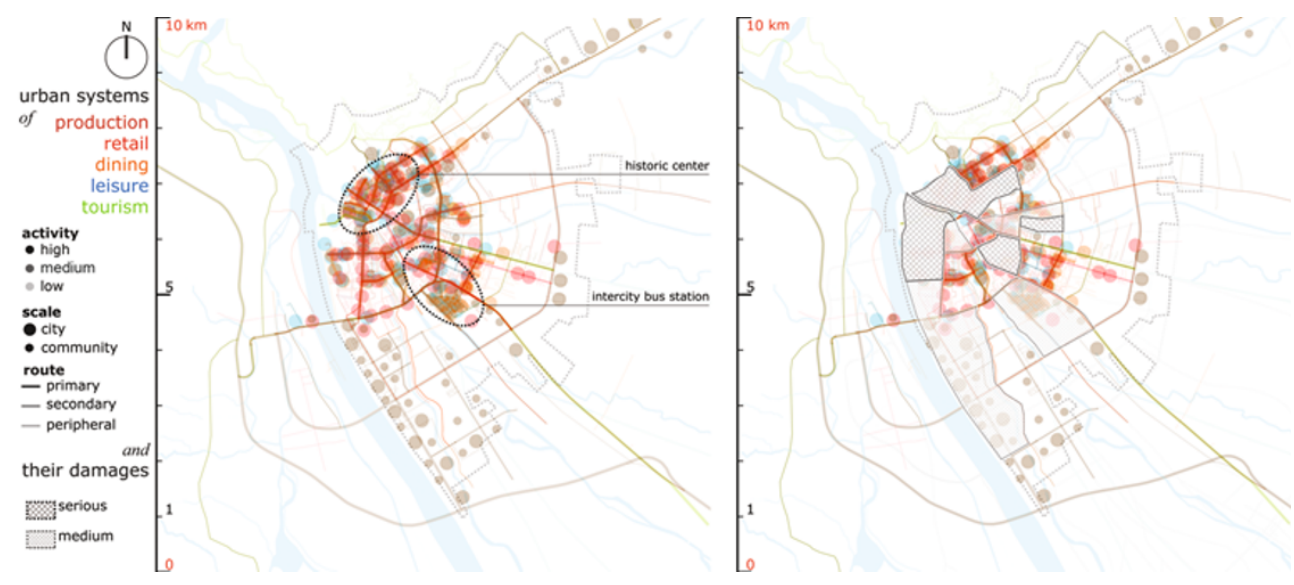

Figure 5. The original pattern of Dujiangyan's urban systems (a) and their damages after the May 2008 Great Sichuan Earthquake (b)

Source: Guo 2010 
urban area, the city center, has been mostly eliminated. This explains why the damage has not only largely ruined the urban fabric, but it has also severely destroyed the urbanity of the city. The argument is that, only repairing or reconstructing the built structures is not sufficient for rebuilding the resilience of the city from the physical damage of the disaster. It is also necessary to pay careful attention to the damage of the urban system and the urban livelihood and to redevelop the sociospatial coherence of the place.

\subsection{An Integral Scenario of Urban Resilience}

"Disasters did neither inevitably destroy cities or societies, nor indeed produce decline. Cities are obdurate and resilience is there for perhaps as long as cities themselves exist" (Coaffee, Wood, and Rogers 2009, 17). Yet, with the changes to urban form and civic governance structures in response to natural hazards, disasters can act as a stimulus to encourage post-disaster rebuilding and innovation. Urban administrations often emphasize "that their city has come back stronger than ever" (Vale and Campanella 2005, 17).

The alternative proposal (Guo 2010) investigates how to construct a resilient city from the disaster with an independent yet critical point of view as an urban professional. In this task, the goal is to seek integral development interests based on the resources that the government would provide, yet to fulfill the needs of the city and its social groups, by initiating new urban programs and designing urban projects to promote urban resilience. Figure 6 is a result of this design exercise, showing an alternative scenario to the vision of the government, to lead the city into a more resilient future through its transformation in the reconstruction. It tries to integrate the intention of the government on tourism development in the region based on the local resources, and to improve the urban- ity by recognizing the original social and spatial quality, which has been considered as the pattern of the urban resilience that has existed for thousands of years in Dujiangyan. This interpretation of urban resilience pays extra attention to the city's rural demography and economy and productive agricultural landscape, and tries to integrate it into the post-disaster urban transformation. The integration, between tourism development and the existing urban quality, between agriculture, ecological landscape, and the urban expansion, improves the social and spatial coherence, and defines the development for the specific urban profile. Yet the systematic and holistic approach opens up the possibility to continue the significant history of Dujiangyan in its future; that approach is the key of the design proposal.

Given the fact that the future development of Dujiangyan inevitably involves urban expansion, the alternative design proposal argues that in order to use the resources for reconstruction strategically, urban projects should be located either in the extension parts of the city or along related routes to enhance the interrelation with similar facilities in the city; these projects should be located in the new settlements with direct connections to the existing urban route system, so that they create new urbanity by serving the inhabitants in the newly developed neighborhoods and extend the urban system by connecting the existing and new parts together. Urban projects at various spatial scales should create diverse densities of housing and commercial developments along the outer ring road: some with high density of social housing that accommodates the victims who have to move to the periphery of the city; others with larger-scale commercial and leisure facilities along the ring road and its major exits; and commercial and leisure developments on secondary streets or on the streets of neighborhoods that are relatively small in scale, to match the local urban and rural fabric of Dujiangyan, as well

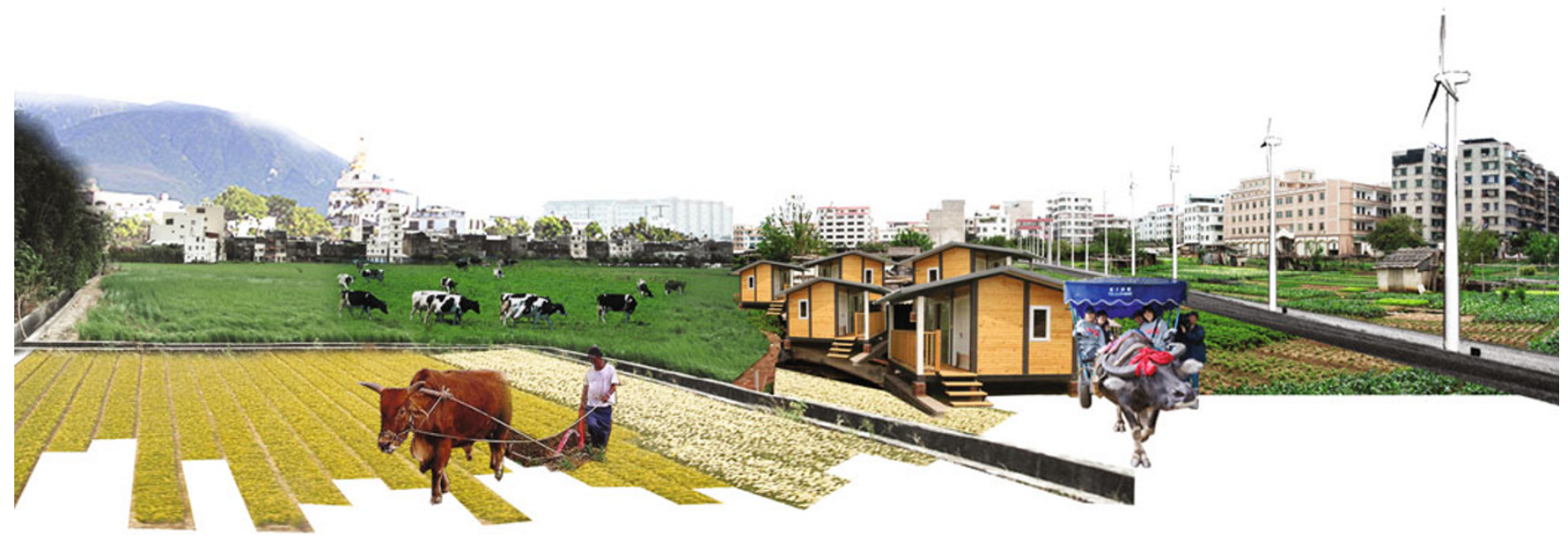

Figure 6. An alternative scenario-Dujiangyan, Sichuan Province: a tourbanistic agropolis for 2012, which integrates sustainable agriculture economy and landscape development and the government's touristic and urbanistic ambition into the urban future

Source: Guo 2010. 


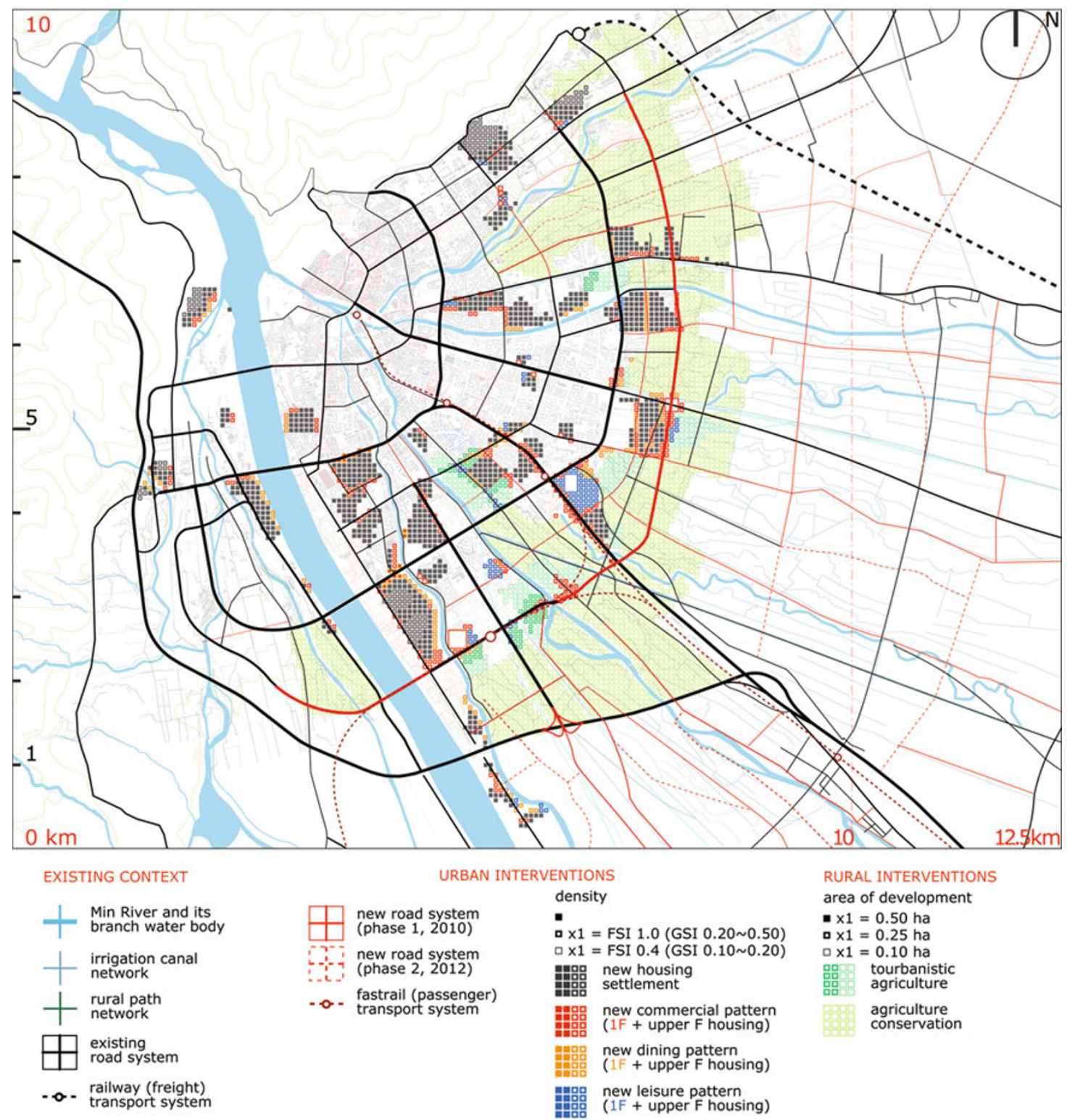

Figure 7. Alternative development scenario for Dujiangyan, Sichuan Province

FSI: Floor Space Index (also known as FAR, Floor Area Ratio), which is the total covered area on all floors of all buildings on a certain plot divided by the area of the plot; GSI (Ground Space Index) equals to constructed area divided by surface area.

Source: Guo 2010.

as to reduce the risk of disasters by dispersing settlement (Figure 7).

In order to make the city more resilient, a further phase after the reconstruction is also proposed, in a continuous line of urban development, to extend the road networks into the surrounding villages, following some corresponding smallscale developments of facilities and landscapes along the way. By reinforcing the connection between the urban and the rural, it integrates the urban inhabitants' and farmers' networks of daily exchange, trade, social contact, and participation in each other's lives - the city of Dujiangyan becomes a coherent and integral whole.

\section{Conclusion}

The post-disaster reconstruction in Sichuan guided by the government has been a notable success in many aspects, such as emergency response and relief, economic revival and construction efficiency, political achievement and social image promotion, as well as the fact that there was an innovative emergence and remarkable involvement of NGOs during the post-disaster relief period. For many remote rural places, it has been the opportunity of a lifetime to be part of the blueprint, which promises to upgrade the local built environment in ways none of its residents ever expected. 
But none of the official documents or urban plans of reconstruction and redevelopment seems to indicate that urban resilience is treated as an intentional, integral part of the government vision. One of the keys to maintaining and improving the resilience of a city is the integration between top-down planning and bottom-up demands from relief to reconstruction phases, and it is missing in the Sichuan Earthquake case. Instead, the dominant top-down planning did not integrate, or not as much as expected, the bottom-up initiatives to reflect the cities' actual demand for development, but promoted a generic development at many individual postdisaster sites. Such ignorance of the local cultural context and site-specific resilience cannot be considered sustainable.

Developing urban resilience of a post-disaster city calls for sociospatial coherence in the urban plans and projects, temporal continuity of the urban interventions, and interdisciplinary and multistakeholder integration and communication. To achieve this, it is necessary not only to repair or reconstruct what has literally collapsed in the disaster. It is critical to interpret an urban resilience in the specific post-disaster urban context of the many urban components, elements, networks, dynamics, and capacities. It requires attentive and inclusive consideration in planning and design of the scales, tools, approaches, and intensity of the intervention, instead of rapid and generic urbanization or interruption to the urban system with radical social and spatial changes that decreases these systems' capacity to cope with future disasters.

Even though the achievements in Sichuan post-disaster reconstruction have been significant and the government interventions are technologically advanced and organizationally efficient, disaster recovery in China still lacks sufficient support for the integration of various stakeholders, as well as sociospatially coherent and holistic redevelopment scenarios. Seeking urban resilience can be an arduous task, but the exploration of alternative scenarios indicates that it is possible.

\section{Notes}

i Urbanity is considered as a core concept in the field of urbanism. In general, it can be described as the characteristic of a city or the quality of an urban space. It has to do with the "hard" entities, such as built form and spatial condition of the urban fabric; it also has to do with the "soft" aspects, such as demographic settings, social activities, political regime, and economic dynamics that are associated with the daily urban livelihood, which are held in the urban fabric.

ii Based on the March 2012 exchange rate of USD 1 = RMB 6.29.

iii Right after the Great Sichuan Earthquake, the government executed the post-disaster rescues and relief with impressive efficiency by coordinating military forces and an enormous number of volunteers. Approximately 4.9 million volunteers joined the relief effort (512 Help 2008). Soon after, 19 other provincial governments were ordered to assist the local municipalities with post-disaster reconstruction. This has been the most efficient post-disaster relief action in China, integrating governmental and military forces, NGO initiatives, technical experts, and business contributions in a very short time. iv The Sichuan Workshop: Dujiangyan Dreams was an interuniversity and interdisciplinary summer workshop (19 July-6 August 2010) carried out in Sichuan, with a group of teachers and Masters of Science students in Urbanism, Architecture, Building Technology, and Real Estate \& Housing from the Faculty of Architecture at Delft University of Technology and postgraduate students in the European Masters in Urbanism (EMU) from four leading European universities (Universitat Politecnica de Catalunya, Spain; Delft University of Technology, The Netherlands; Katholieke Universiteit Leuven, Belgium; and Università IUAV di Venezia, Italy), as well as teachers and undergraduate/graduate students in the School of Architecture at Southwest Jiaotong University, China. The workshop was initiated by the author.

$v$ To optimize the efficiency of relief, the government introduced a strategic policy to involve NGO initiatives after the Great Sichuan Earthquake. With this support, the number of NGOs has risen to approximately three hundreds, involving three million volunteers (Lin and Zhan 2010).

vi Direct-Controlled Municipality (DCM) is the highest level classification for cities in China with a status that equals that of provinces.

\section{References}

512 Help (NGO). 2008. Searching for Relatives in the Aftermath of the Wenchuan Earthquake. http://www.512help.org/ (in Chinese).

Bull-Kamanga, L., K. Diagne, A. Lavell, F. Leon, F. Lerise, and H. MacGregor. 2003. From Everyday Hazards to Disasters: The Accumulation of Risk in Urban Areas. Environment and Urbanization 15 (1): 193-204.

Carpenter, S., B. Walker, J. M. Anderies, and N. Abel. 2001. From Metaphor to Measurement: Resilience of What to What? Ecosystems No. 4: 765-81.

Chengdu Planning and Management Bureau. 2008. New Home: Achievement Show of Chengdu Post-Quake Reconstruction Planning. http:// www.cdgh.gov.cn/structure/lm zhcj/xjy nr?infid=7.

Coaffee, J., D. M. Wood, and P. Rogers. 2009. The Everyday Resilience of the City, How Cities Respond to Terrorism and Disaster. Houndmills, Basingstoke, Hampshire: Palgrave Macmillan.

Dovers, S. R., and J. W. Handmer. 1992. Uncertainty, Sustainability and Change. Global Environmental Change 2 (4): 262-76.

Ge, Y., Y. T. Gu, and W. G. Deng. 2010. Evaluating China's National Post-Disaster Plans: The 2008 Wenchuan Earthquake's Recovery and Reconstruction Planning. International Journal of Disaster Risk Science 1 (2): 17-27.

Godschalk, D. R. 2003. Urban Hazard Mitigation: Creating Resilient Cities. Natural Hazards Review 4 (3): 136-43.

Goldstein, B. E. 2011. Collaborative Resilience: Moving Through Crisis to Opportunity. Cambridge: MIT Press.

Gunderson, L. H. 2000. Ecological Resilience - In Theory and Application. Annual Review of Ecology and Systematics 31: 425-39.

Guo, Y. 2010. Integralism: From a Post-Disaster City towards the Tourbanistic Agropolis of Dujiangyan, Sichuan. European Postgraduate Master in Urbanism (EMU), Delft University of Technology.

Holling, C. S. 1973. Resilience and Stability of Ecological Systems. Annual Review of Ecology and Systematics No. 4: 1-23.

Kuang, X., and J. Jiang. 2010. 60 Years of China's Urbanization: 19492009. Urban China 40: 36, 41, 42 (in Chinese).

Lin, M., and J. Zhan. 2010. NGO Involvement and Management in Post-disaster Relief. Administrative Management of China No. 3. http://www.usc.cuhk.edu.hk/PaperCollection/Details.aspx?id=7547 (in Chinese).

Pelling, M. 2003. The Vulnerability of Cities: Natural Disasters and Social Resilience. London: Earthscan.

Pelling, M., and C. High. 2005. Understanding Adaptation: What Can Social Capital Offer Assessments of Adaptive Capacity? Global Environmental Change 15 (4): 308-19. 
Potangaroa, R., M. J. Wang, and Y. Chang. 2008. Identifying Resilience in Those Affected by the 2008 Sichuan Earthquake. Engineering Management Forum 2008. Erdos, China. http://www.resorgs.org.nz/ pubs/Resilience\%20in\%20Sichuan\%20Regan2.pdf.

Resilience Alliance. 2009. Assessing and Managing Resilience in Social-Ecological Systems: A Practitioner's Workbook. http://wiki. resalliance.org/index.php/Main_Page.

State Council of the People's Republic of China. 2008. Post-Wenchuan Earthquake Restoration and Reconstruction Ordinance (No. 526). http://www.gov.cn/zwgk/2008-06/09/content_1010710.htm.
Timmerman, P. 1981. Vulnerability, Resilience and the Collapse of Society: A Review of Models and Possible Climatic Applications. Institute for Environmental Studies, University of Toronto, Canada.

UNCRD (United Nations Centre for Regional Development). 2009. Report on the Great Sichuan Earthquake in China. http://www.hyogo. uncrd.or.jp/publication/pdf/Report/Sichuan/sichuan.eng.pdf.

Vale, L. J., and T. J. Campanella. 2005. The Resilient City: How Modern Cities Recover from Disaster. Oxford: Oxford University Press.

Open Access This article is distributed under the terms of the Creative Commons Attribution License which permits any use, distribution, and reproduction in any medium, provided the original author(s) and source are credited. 